\title{
BMJ Open Quality Increasing the uptake of cervical screening at cornerstone medical practice
}

\author{
Adeola Oyegbite, ${ }^{1,2}$ Jessica Roberts, ${ }^{3}$ Joanna Bircher ${ }^{4}$
}

To cite: Oyegbite A, Roberts J, Bircher J. Increasing the uptake of cervical screening at cornerstone medical practice. BMJ Open Quality 2021;10:e001126. doi:10.1136/ bmjoq-2020-001126

Received 27 July 2020 Accepted 31 August 2021
Check for updates

(C) Author(s) (or their employer(s)) 2021. Re-use permitted under CC BY-NC. No commercial re-use. See rights and permissions. Published by BMJ.

${ }^{1}$ Salford Care Centres, Salford, UK

${ }^{2}$ NHS Salford CCG, Salford, UK

${ }^{3}$ Salford Royal Hospital, Salford, UK

${ }^{4}$ Lockside Medical Centre, Stalybridge, UK

Correspondence to Dr Adeola Oyegbite; adeola.oyegbite@nhs.net

\section{ABSTRACT}

Background Nationally, cervical screening uptake is suboptimal, even though research shows that the programme is highly effective at preventing cervical cancer.

Local problem Cornerstone is a small practice located in Salford in the North West of England. Historically, screening uptake here has been lower than average. There were 656 eligible women on our practice list and 177 of them were unscreened at the start of the project. The largest group of non-white British or Irish people on our list (13) spoke Polish as their first language.

Methods We used quality improvement methods: the model for improvement, a driver diagram and Plan, Do, Study, Act cycles. Specifically, we targeted 177 women who were previously non-responders, as well as keeping up the regular screening service. We managed to contact 120 women during the project.

Interventions We tested different methods of inviting women to attend cervical screening: telephone calls, text messages and letters. Later, a video link was also included in the text invitation. Information leaflets about the tests were added to letters. The letter was also translated into Polish.

Results Uptake improved and the aim was reached. Telephone calls from the nurse increased uptake but took time away from other work, so was not a sustainable change for our practice. A letter stating evidence basis for the test, and a letter translated into Polish showed limited improvement. Sending letters with information leaflets and text messages with video links achieved similar response rates with no statistical significance when we analysed the data. Offering extended hours and flexible appointment times showed very positive results.

Conclusions The text message with a video attached was adopted as an effective method for targeting persistent non-responders.

The project in its second year is being scaled up across the Primary Care Network.

\section{PROBLEMI DESCRIPTION}

Cervical cancer is $99.8 \%$ preventable, yet in the UK, approximately 9 women are diagnosed with cervical cancer daily. A total of 854 women died from cervical cancer in 2016 and this is set to rise if current trends continue. $^{1}$

One method for preventing cervical cancer is the human papillomavirus (HPV) vaccines.
This vaccination programme started in England in September 2008 for girls aged 12-13 and September 2019 for boys of the same age. ${ }^{2}$ Vaccinated females in England are still advised to undergo cervical screening when they reach the age of 25 as the vaccine does not protect against all subtypes of HPV. ${ }^{3}$ Hence at present, cervical screening remains a key preventative measure for cervical cancer. This project focused on cervical screening uptake to keep our aim specific.

Reversing the trend of falling screening uptake presents a public health challenge. This has been identified as an area of priority by Salford Clinical Commissioning Group (CCG). Salford CCG, therefore, funded a general practitioner quality improvement fellowship to address screening uptake starting at the practice level.

Cervical screening is for anyone classed as female at birth. In the UK, the test is offered between the ages of 25 and 65 . The current process for screening invitation involves an invitation and a reminder letter sent directly to patients from Public Health England (PHE). ${ }^{4}$ PHE notifies the practice if women do not respond to the invitations. The practice then invites the women using letters, text messages, telephone calls or opportunistic invitations when at the practice.

Cornerstone practice had made many attempts to improve screening uptake prior to this project but the uptake levels had plateaued around $73 \%$ according to the practice's own digital audits. There were 656 eligible women on our list at the start of the project and 177 (27\%) of them on the nonresponder list. Our strategy was to target the non-responders while maintaining our usual service.

\section{AVAILABLE KNOWLEDGE}

According to research by Jo's Trust, a charity that promotes cervical screening, there is no single reason why women do not attend cervical screening. The Trust suggests 
discovering which population/s are less likely to attend locally before designing an intervention. It also recommends focusing on improving promotion, access, incentives, outreach and practice awareness and education. ${ }^{5}$ This project focused mainly on improving promotion and access.

One approach tried was for the practice nurse to call patients in for their tests. This was attempted prior to commencement of the project and therefore analysed retrospectively. We counted the number of tests completed in the month following the phone calls and the proportion who had received a phone call from the nurse. Sixteen tests were booked for August 2018 from the general unscreened group. Fourteen were completed and two did not attend. Seven out of 14 had prior nurse contact. The total number of phone calls made by the practice nurse was unclear.

We decided to trial invitation ideas which would take less of the nurse's time. The practice nurse would continue to invite women over the phone or in person when the opportunity arises and code this in their records so we could monitor the effect. The numbers were later included in the data analysis.

\section{RATIONALE}

The model for improvement was applied to the problem. The model describes three questions that must be answered before any of the work begins, in order to define the scope of the project, how achievement of the aim will be measured, and plan ideas for change. ${ }^{6}$
A driver diagram shown in figure 1 was used to generate change ideas. Plan, Do, Study, Act (PDSA) cycles were used to plan, undertake, analyse and make decisions on whether to adopt the interventions. The practice team was involved in discussing the challenges as well as suggesting and refining change ideas from the outset.

\section{SPECIFIC AIMS}

The aim of the project was to increase the rates of cervical screening uptake to $80 \%$ in Cornerstone Medical Practice by 31 March 2019 .

The aim was based on the CCG desirable uptake rates and the deadline to earn associated Quality and Outcomes Framework (QOF) points. QOF is a payment by results system introduced in 2004 to incentivise highquality care in English general practices. The aim is specific in its scope of cervical screening at Cornerstone Medical Practice, measurable by its target of $80 \%$ uptake, and time-bound, as completion of the project was the end of March 2019. Aims with these attributes are more likely to succeed, according to the Institute of Healthcare Improvement. ${ }^{7}$

\section{CONTEXT}

Cornerstone Medical Practice is a small practice with a list size of approximately 2000 patients. It is located in the Ordsall and Claremont Primary Care Network (PCN), specifically in the ward of Langworthy. Overall, the network has a population of around 42000 people. ${ }^{8}$ Langworthy is Salford's most deprived ward. It has a higher

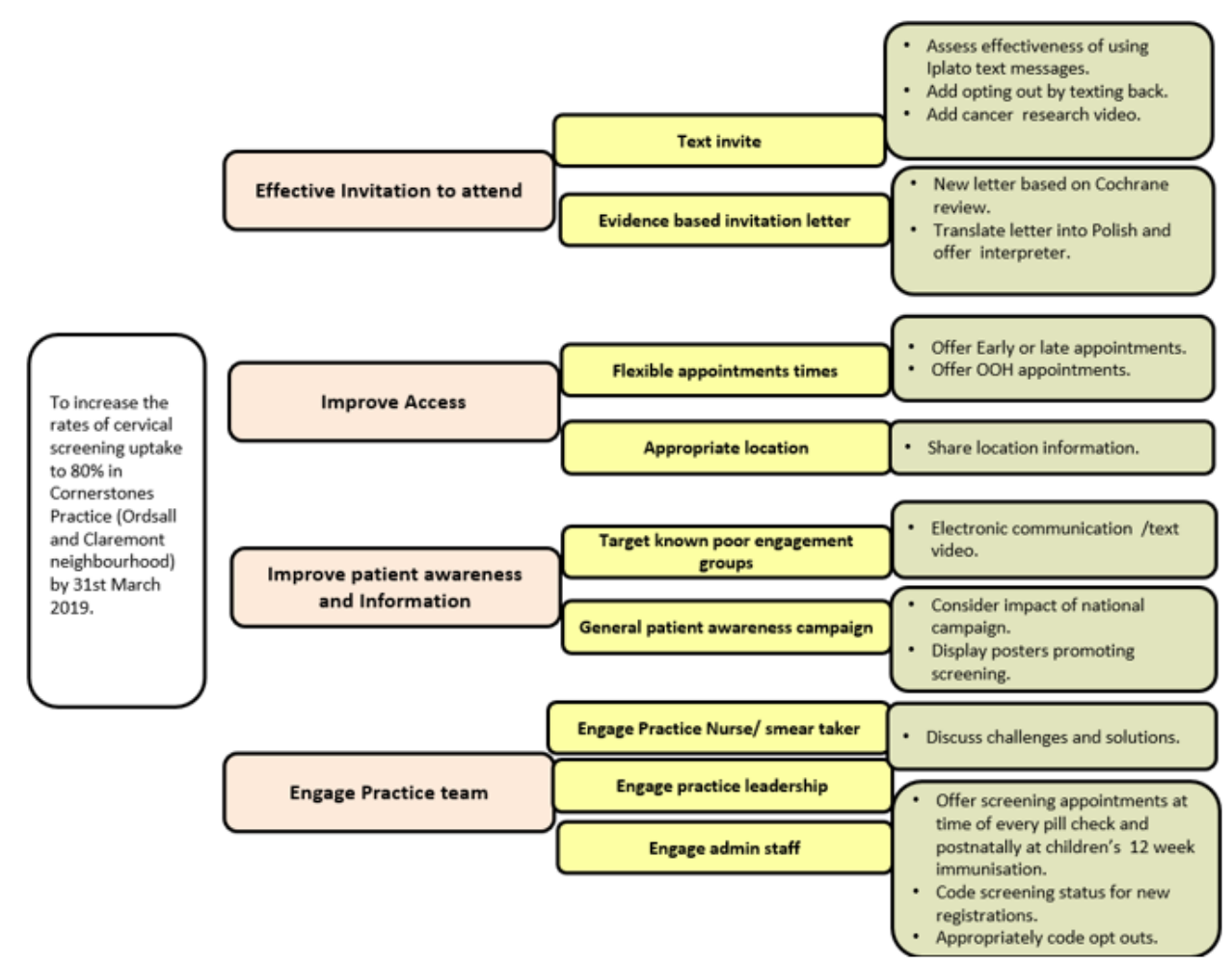

Figure 1 Driver diagram-driver diagram to generate change idea. $\mathrm{OOH}$, out of hours. 
composition of young adults compared with Salford as a whole. ${ }^{9}$ This is reflected in our practice population where almost half of all women who require screening are under the age of 35 .

The Black, Asian and Minority Ethnic (BAME) population in Langworthy is 19\% which is similar to England as a whole but higher than the Salford's overall 14\%. The BAME population includes all non-white British or Irish people. The largest individual BAME group in Langworthy is black African $(5.1 \%)$ and the second is white other $(4.6 \%)$, which includes Eastern Europeans. ${ }^{10}$ Polish was the most common foreign language (7\%) among women on our non-responder list.

\section{INTERVENTIONS \\ PDSA 1}

The practice had sent text messages in June 2018. We went back through a sample of women's notes to collect and analyse the effect of this intervention. This was an important baseline to establish and it guided the next interventions.

Plan: Send text messages to persistent non-responders to remind them to book in for their screening. We analysed the results retrospectively. It was done by practice staff.

Do: We counted the number of women who responded out of the sample who were sent text messages.

Study: Three out of 10 women receiving text messages responded. Two out of the 10 messages were not delivered. Five out of 10 women did not respond to the message.

Act: Add video on screening to next set of text messages. Include option to text back to decline.

As a result of this PDSA cycle, we adapted our methods and carried out PDSA 2 and PDSA 3.

\section{PDSA 2}

We ensured women who made informed decisions to decline screening via text message were appropriately coded.

Plan: We included an option for women to text back to decline screening and ensure all patients who had declined screening were appropriately coded. This was done by practice staff.

Do: All patients who have made an informed choice to decline were appropriately coded.

Study: Only fourwomen who received text messages during this project texted back to decline screening. They were appropriately coded.

Act: The practice team will ensure coding is done regularly to keep the list accurate.

\section{PDSA 3}

We provided the following video link as part of text message invitations https://www.youtube.com/watch?v= QjuEYqQvb0E.

Plan: Attach Cancer Research UK animated video link to text messages to provide more information on the test. This was done by practice staff.
Do: A short text message with link to the video was sent to women.

Study: Three out of 10 women invited responded to the text message. A new balance measure was discovered when a test was done too early and rejected by the lab.

Act: Add new balance measure and monitor numbers. Check central databases for screening information on new patients and update records. Although the addition of the video link made no difference to response rates, we decided to include it in future messages as a way of providing more information for those who wanted it.

\section{PDSA 4}

Updating patient records avoided further unnecessary screening tests.

Plan: Ensure all newly registered patients have their cervical screening status accurately entered on the system. To be completed by admin team.

Do: We created a list of unscreened patients who had been registered for 3 months or less and the admin team checked their screening status.

Study: None of the patients on the list had an up-to-date test.

Act: All the patients on this list were invited for screening. The practice will include this check as part of the registration process for eligible women in the future.

\section{PDSA 5}

The invitation letter was redesigned to include evidence basis for the test.

Plan: Newly designed letters with appropriate details were sent to 10 women. The aim was for $50 \%$ response in the following month. This was done by practice staff.

Do: The proportion of women who responded was counted.

Study: Two of the 10 attended for their screening test. Eightwomen did not respond. This was a much lower response rate than predicted. We thought a language barrier may account for some non-responders.

Act: Translate letter into Polish and send out to relevant women.

\section{PDSA 6}

The new letter was translated into Polish. This was the most common foreign language in our unscreened population. We added a sentence to inform women that interpreters were available. This PDSA showed translation did not make much difference.

Plan: Add offer of interpreters and send translated letter. Aim for $50 \%$ response. This was done by the deputy practice manager.

Do: The invitation letter was translated and sent out to the relevant women.

Study: Only 3 of the 13 women responded. Two tests were done. One was cancelled due to illness.

Act: Translating letters and offering interpreters did not engage significantly more women in this case, and 
other reasons for not responding are likely. We abandoned translated letters.

\section{PDSA 7}

Patient feedback was obtained to help understand the low response rates.

Plan: Gather information to understand reasons for non-responders. We predicted patients will give some insight into their reasons for not engaging. This was done by the project lead.

Do: Ask patients to describe why they have not attended in their own words. We were only able to speak to 7 patients of the attempted 30 phone calls.

Study: Three patients reported that they were unsure what the test was or what they had to do next. Four patients reported lack of evening or weekend (out of hours $(\mathrm{OOH}))$ appointments was a barrier to their attendance. Telephone calls during working hours may have reduced our ability to reach some women.

Act: As a result of this PDSA, we included information leaflets in subsequent letters sent to women. The letter was redesigned to make the next steps clearer. This PDSA reinforced our decision to include video links in text invitations. We also decided to offer flexible appointments to women who wanted them.

\section{PDSA 8}

An information leaflet from PHE was sent with the letter as a result of the feedback in the last PDSA.

Plan: This was done by the project lead. We predicted $50 \%$ of previously non-responding women will respond.

Do: The letter was printed, leaflets included and sent to 10 women.

Study: Three out of the 10 women invited attended for screening. This is a similar rate to women invited via text messages with video attachments.

Act: Due to the number of admin hours involved and higher cost of postal communication, we will only contact women in this way if not responding to text messages.

\section{PDSA 9}

As a result of the patient feedback we offered flexible appointments to those unable to attend during working hours.

Plan: Offer flexible appointments to suit patients.

Do: We offered early or late appointments and a few with the local $\mathrm{OOH}$ service. The $\mathrm{OOH}$ service was provided across the PCN.

Study: Of the sevenwomen who contacted us with inability to attend due to working hours, six accepted and five attended early, late or $\mathrm{OOH}$ appointments. The rate of uptake given flexible appointments was encouraging.

Act: We plan to continue to offer early and late appointments in the practice. The availability of future $\mathrm{OOH}$ appointments will depend on analysis of the impact of these appointments across the PCN. The impact of flexible appointments still depends on women getting in touch once invited.

\section{PATIENTS AND PUBLIC INVOLVEMENT STATEMENT}

We did not include patients or the public in the design or reporting of this project. Patient input was sought in PDSA 7 and it guided PDSA 8 and 9.

\section{RESULTS}

\section{Measures}

We developed a measurement strategy which involved using an electronic source for collecting data related to the aim. We counted numbers to monitor progress for primary drivers and collected qualitative data from the survey.

\section{Measurement 1: outcome}

A series of activities over the duration of the project contributed to successful achievement of the aim. Figure 2 is a run chart of the outcome measure with the various activities highlighted.

PHE's national cervical screening campaign started in the last 3 weeks of the project and this is likely to have had some positive impact as well.

\section{Measurement 2: practice engagement}

The practice team's engagement was very high with seven out of nine PDSA cycles done by practice staff.

\section{Measurement 3: PDSA}

The outcome and analysis from each PDSA cycle is documented above. There is additional analysis of each intervention type below.

\section{Measurement 4: telephone survey}

Four out of the seven patients reported appointment times as the barrier.

Three out of seven patients did not understand the information well enough to make a decision.

\section{Measurement 5: inappropriate tests}

There were two screening tests done before they were due.

\section{DATA ANALYSIS}

Out of 177 records in total, 57 were excluded from data analysis. Reasons for exclusion were: 26 patients received no contact during the period of the project. This was because they had been contacted just prior to the project period and they had not responded. Fourwomen were exempt from analysis because they had never been sexually active. They are at low risk of cervical cancer therefore we did not target them during this project. One woman had turned 65 and did not want the test. Two women were pregnant and so screening was inappropriate. Twentyfour women transferred out of the area during the project.

Of the 120 women included in analysis, the intervention for 8 screened women was either unclear or unknown. It was not possible to assign them to a group so they were also excluded from the data analysis. This left a total number of 112. 


\section{PERCENTAGE OF WOMEN SCREENED BY MONTH}

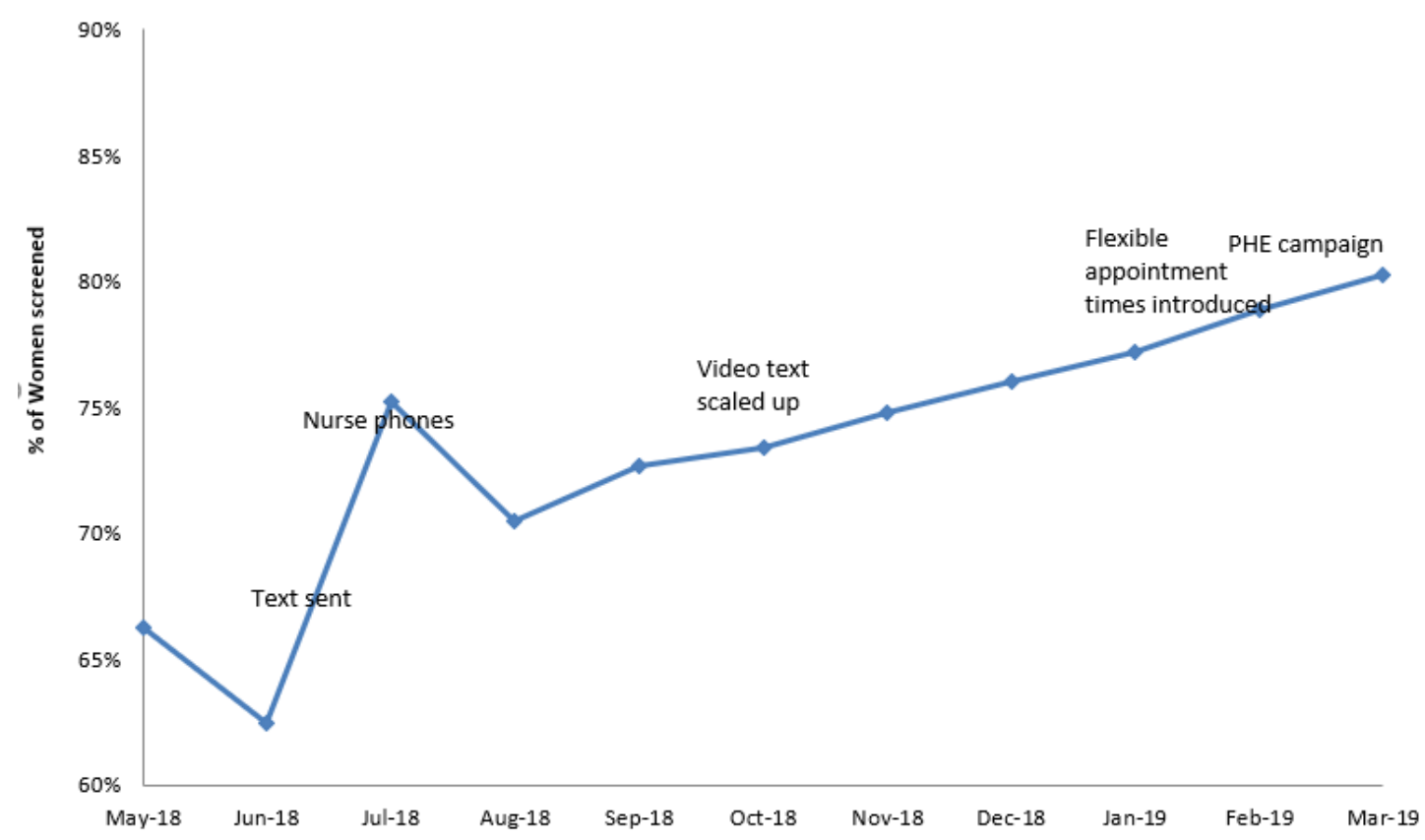

Figure 2 Outcome chart-chart showing percentage of all eligible women screened over time. PHE, Public Health England.

The data were split into three groups based on their last intervention; letters of any type (25); nurse contact (8); text messages of any type (79).

Figure $3 \mathrm{~A}$ shows the percentage of each cohort that responded to the contact. A woman was counted as a responder if she booked an appointment for screening or made an informed decision to decline it. The highest response rate was when the nurse invited women. As this is sample data, we applied 95\% CIs. These show no statistical difference between the cohorts-the lack of statistical difference for the nurse cohort is due to its small size of 8 .

Figure 3B shows the percentage of each cohort that had the screening done. Nurse contact has a slightly higher rate but, again, the application of $95 \%$ CIs shows no statistically significant difference between the cohorts.

\section{SUMIMARY}

We achieved the project aim of screening $80 \%$ of all eligible women by March 2019.

As a result of the PDSA cycles, text messages with video links were scaled up to contact all non-responders. Where there is no valid telephone number, letters and leaflets are sent.

\section{INTERPRETATION}

The data analysis showed no statistical difference between methods of invitation and response or screening rates.

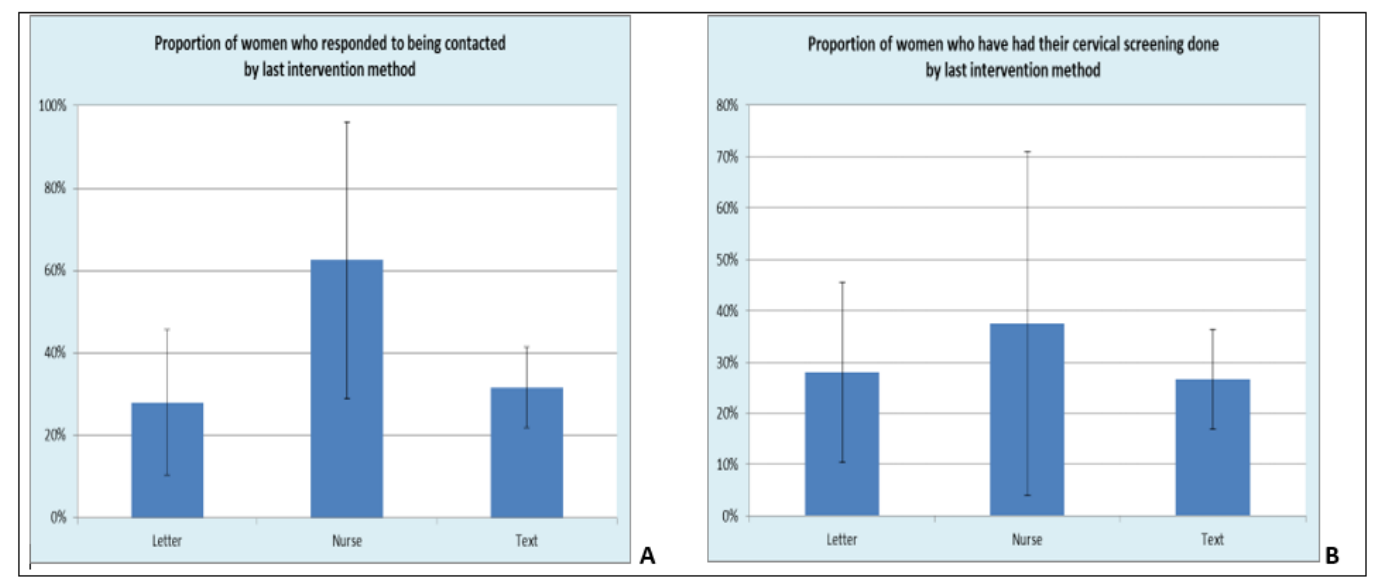

Figure 3 (A) Analysis of response by last intervention. (B) Analysis of screening by last intervention. 
Nurse contact may improve uptake compared with other methods but the numbers contacted were small as contacting women needed to be balanced against her other duties. She continues to invite women where the opportunities arise.

The survey showed that we still have a lot of work to do in communicating the pros and cons of screening in order for women to make informed choices.

Making appointments more conveniently timed was the other key issue revealed by patients. We found many women will accept an early or late appointment which fits round their daily commitments.

Fortunately, once we identified our balancing measure, we were able to take action to prevent further occurrences.

\section{LIMITATIONS}

The main limitation of these results is that most patients on our list received multiple types of invitation over the period they failed to respond. This includes their initial letters of invitation from PHE. It is unclear whether the last invitation directly led to their response and subsequent screening.

We collected data on weekly attendance for screening and as a small practice we found our median number was only four screening tests per week. The very small numbers made it very difficult to demonstrate any significant shifts in numbers attending over time.

\section{CONCLUSION}

As a team we plan to hold on to our gains and continue to use small tests of change to improve our numbers. We are keen to share our learning with other practices and learn from their experiences to help improve the care of more patients.

The project will be scaled across the network this year. The next steps are to continue to measure and adapt interventions across the PCN under the leadership of our practice manager.

Twitter Joanna Bircher @joannabircherQl

Acknowledgements Cornerstone Medical Practice team, Advancing quality Alliance (AQuA), Haelo.

Contributors This manuscript is result of work carried out by a number people from Cornerstones Medical Practice and Advancing Quality Alliance (AQuA). Our contributions are as follows. A0: Substantial contributions to the conception, design of the work and the acquisition of data. JR: Drafting the work for important intellectual content. JB: Revising the work critically for important intellectual content. Colin Malcolmson: Support for design, planning and carrying out of the work. Ina Pownall: The collection of data and general supervision of interventions. Beverley Owens: Carrying out interventions and conducting the screening test. Jessica Higgins: Carrying out the interventions. Donna Thorpe: Carrying out the interventions. Paul Hawgood: Analysis and interpretation of data. Elizabeth Bradbury: Supporting application for funding.

Funding This study was funded by Salford Clinical Commissioning Group and Safer Salford Programme.

Competing interests None declared.

Patient and public involvement Patients and/or the public were not involved in the design, or conduct, or reporting, or dissemination plans of this research.

Patient consent for publication Not required.

Provenance and peer review Not commissioned; externally peer reviewed.

Data availability statement Data are available in a public, open access repository. All data are available in public, open access repository or included in the article.

Open access This is an open access article distributed in accordance with the Creative Commons Attribution Non Commercial (CC BY-NC 4.0) license, which permits others to distribute, remix, adapt, build upon this work non-commercially, and license their derivative works on different terms, provided the original work is properly cited, appropriate credit is given, any changes made indicated, and the use is non-commercial. See: http://creativecommons.org/licenses/by-nc/4.0/.

\section{REFERENCES}

1 Cancer research UK. Cervical cancer statistics, 2019. Available: https://www.cancerresearchuk.org/health-professional/cancerstatistics/statistics-by-cancer-type/cervical-cancer [Accessed 6 Jun 2019].

2 National Health Service. England. HPV vaccine overview, 2019. Available: https://www.nhs.uk/conditions/vaccinations/hpv-humanpapillomavirus-vaccine/ [Accessed 20 Jul 2020].

3 Public health England guidance. cervical screening: programme overview, 2021. Available: https://www.gov.uk/guidance/cervicalscreening-programme-overview [Accessed 20 Jul 2021].

4 Public Health England. Cervical screening: guidance for call and recall administration best practice, 2021. Available: https://www. gov.uk/government/publications/cervical-screening-call-and-recalladministration-best-practice/cervical-screening-call-and-recall [Accessed 20 Jul 2021].

5 Jo's Trust. Increasing screening attendance. Available: https:// www.jostrust.org.uk/professionals/health-professionals/increasingscreening-attendance [Accessed 3 Feb 2020].

6 Langley GJ, Moen RD, Nolan KM. The improvement guide: a practical approach to enhancing organizational performance. New Jersey: Jossey-Bass Publishers, 2009.

7 The Institute for healthcare improvement. setting aims. Available: http://www.ihi.org/resources/Pages/Howtolmprove/Scienceoflmp rovementSettingAims.aspx [Accessed 3 Feb 2020].

8 Langworthy ward profile (p.6-7). Available: https://www.salford.gov. $\mathrm{uk} / \mathrm{media} / 395080 /$ langworthy-ward-profile-jan-2020.pdf [Accessed 3 Mar 2020].

9 Langworthy ward profile (P. 9-10). Available: https://www.salford.gov. uk/media/395080/langworthy-ward-profile-jan-2020.pdf [Accessed 3 Mar 2020].

10 Langworthy ward profile (p.16). Available: https://www.salford.gov. $\mathrm{uk} / \mathrm{media} / 395080 /$ langworthy-ward-profile-jan-2020.pdf [Accessed 3 Mar 2020]. 